\title{
A Regression-Based Approach to Estimating Retrofit Savings Using the Building Performance Database
}

\author{
Travis Walter ${ }^{\mathrm{a}, \mathrm{b}, *}$, Michael D. Sohn ${ }^{\mathrm{a}}$ \\ ${ }^{a}$ Energy Analysis and Environmental Impacts Division, Lawrence Berkeley National Laboratory, Berkeley, CA, USA \\ ${ }^{b}$ Civil and Environmental Engineering Department, University of California, Berkeley, CA, USA
}

\begin{abstract}
Retrofitting building systems is known to provide cost-effective energy savings. However, prioritizing retrofits and computing their expected energy savings and cost/benefits can be a complicated, costly, and an uncertain effort. Prioritizing retrofits for a portfolio of buildings can be even more difficult if the owner must determine different investment strategies for each of the buildings. Meanwhile, we are seeing greater availability of data on building energy use, characteristics, and equipment. These data provide opportunities for the development of algorithms that link building characteristics and retrofits empirically. In this paper we explore the potential of using such data for predicting the expected energy savings from equipment retrofits for a large number of buildings. We show that building data with statistical algorithms can provide savings estimates when detailed energy audits and physics-based simulations are not cost- or time-feasible. We develop a multivariate linear regression model with numerical predictors (e.g., operating hours, occupant density) and categorical indicator variables (e.g., climate zone, heating system type) to predict energy use intensity. The model quantifies the contribution of building characteristics and systems to energy use, and we use it to infer the expected savings when modifying particular equipment. We verify the model using residual analysis and cross-validation. We demonstrate the retrofit analysis by providing a probabilistic estimate of energy savings for several hypothetical building retrofits. We discuss the ways understanding the risk associated with retrofit investments can inform decision making. The contributions of this work are the development of a statistical model for estimating energy savings, its application to a large empirical building dataset, and a discussion of its use in informing building retrofit decisions.
\end{abstract}

Keywords: building energy data, retrofit savings, linear regression, uncertainty

\footnotetext{
${ }^{*}$ Corresponding author

Email addresses: twalter@lbl.gov (Travis Walter), mdsohn@lbl.gov (Michael D. Sohn)
} 


\section{Introduction}

Buildings account for roughly $40 \%$ of total energy end-use and roughly $40 \%$ of carbon dioxide emissions in the United States [1]. Newly-constructed buildings tend to be more energy efficient than existing buildings, but replacement of old buildings by new buildings is very slow (roughly $2 \%$ per year). In order to meet energy reduction goals, rapid improvement of building energy efficiency is needed [2]. Compared to replacing old buildings with new buildings, retrofitting existing buildings is a viable approach to reducing energy use because of relatively low cost and potentially high adoption rates [3]. Recently, government programs are providing significant financial support for building retrofit programs.

The goal in a retrofit project is to reduce energy use (and energy costs) while maintaining or improving levels of indoor air quality and occupant thermal comfort [4]. The retrofit process typically entails energy auditing and savings estimation, implementation of the retrofit, then post-retrofit measurement and verification. During auditing, building data and characteristics are analyzed to identify areas of energy waste. Based on these results, retrofit options and proposed and compared based on their projected cost and resulting energy savings. The selected retrofit is then implemented, and measurement and verification is used to verify that projected energy savings were achieved and occupant comfort was maintained [3].

While energy efficiency retrofits help reduce energy use, building owners primarily consider retrofit implementation as a financial decision. Building equipment retrofits can reduce energy costs significantly and can increase the value of buildings in real-estate markets [5]. However, they can be costly to implement. Unfortunately, lack of information about energy savings is a major barrier to investment in retrofits (i.e., building owners are less likely to invest if the return on investment is poorly understood). Methods are needed to identify the most cost-effective retrofits, and to provide measures of confidence in the expected savings. This is a difficult proposition because savings estimates contain substantial uncertainty due to climate, behavior, building-specific characteristics, and complex interactions between these effects. It would be beneficial if retrofit implementation were integrated into a framework in which the costs and benefits can be evaluated objectively and quantitatively. To do so would require a new view of how retrofits and valuations are made. We contend that a promising approach is to treat retrofit analysis from a probabilistic point of view, i.e., to characterize the relationship between system design and the likelihood of achieving energy savings.

Meanwhile, market, technology and policy drivers (e.g., smart meters, disclosure laws) have 
resulted in widespread collection of measured data on building characteristics and energy use. The availability of these data has grown in recent years, and is likely to continue growing. These data provide opportunities for the development of algorithms that use empirical data to estimate energy savings associated with building retrofits. These data can improve understanding of design tradeoffs. However, realizing their full utility is an important research priority. A probabilistic approach could be employed to assess the risks of uncertainty. Models that can quantify uncertainty enable building owners to assess energy efficiency opportunities, forecast project performance, and quantify performance risk using empirical building data.

The remainder of this work is organized as follows: Section 2 summarizes previous methods for predicting savings due to retrofits. Section 3 introduces the Building Performance Database and the subset of the database used for analysis. Section 4 presents the multivariate linear regression model developed to estimate energy use, and Section 5 describes how this model is used to predict savings due to implementing retrofits. Finally, Section 6 discusses how savings predictions can be used to inform decision making.

\section{Methods for Predicting Savings}

Building energy consumption is influenced by several complex and interactive effects, ranging from weather and building envelope design to HVAC systems and occupant behavior. Understanding the influence of these effects on energy use is typically done using building energy models. These modeling methods generally fall into three computational categories: 1) physical models (e.g., DOE-2, EnergyPlus), 2) statistical models, and 3) hybrid models. Physical models are typically constructed by summing the heat and energy flow into and out of a building and determining analytical relationships between various building components. Statistical models identify correlations between building properties and environmental conditions and historical energy use data. While they typically do not require detailed understanding of building physics, they do require collection of data to train the statistical model. Hybrid approaches attempt to leverage the benefits of both physical and statistical models by modeling the physical interaction between building components but using data to train models of individual components and systems [6, 7].

Significant research has been done on predicting the effects of building characteristics and equipment on energy use using physics-based models. A discussion of energy simulation techniques and tradeoffs is provided by Siddharth et al. [8]. Many such methods simulate energy use for case studies of specific building types and climates. For example, Al-Ragom [9] models a house 
in a hot and arid climate using DOE-2, Ascione et al. [10] model a historical building in Italy using EnergyPlus, Rahman et al. [11] model an office building in Australia using a front-end to EnergyPlus, and other authors take similar approaches $[12,13,14,15]$. Rather than particular buildings, some methods analyze archetypal buildings and environments $[16,17]$. For example, Chidiac et al. [18, 19] classify buildings as one of three types based on construction year and building characteristics. Other researchers treat energy retrofits as a multi-objective optimization of energy savings, retrofit costs, and other factors, and use physics-based models to predict energy use $[20,21,22,23]$.

There is also prevalent research using statistical models with building characteristics and equipment as predictors of energy use. Some methods focus on predicting energy use, but do not thoroughly discuss prediction of retrofit savings $[24,25,26]$. Other methods focus on only specific building types and environments. For example, Beusker et al. [27] focus on heating energy in sports facilities and schools, Kolter and Ferreira Jr. [25] focus on residential buildings in Massachusetts, and Hsu focuses on buildings in New York City in both [28] and [29]. A variety of different types of statistical models are used in the literature. Kavousian et al. [30] use stepwise selection to choose predictors in a multiple linear regression model, and use factor analysis to remove collinearity between predictors. Baker and Rylatt [31] use clustering, simple regression, and multiple regression. Hsu uses a Bayesian multilevel regression model in [28] to analyze the value of different measurements for predicting energy use, and finds that benchmarking data alone explains energy use as well as benchmarking and auditing data together. In [29], Hsu discusses selection of predictors, develops a hierarchical penalized regression model, and uses cross validation to compare it to other models.

Literature on hybrid approaches to energy savings modeling is also common. For example, Heo et al. [32] calibrate parameters in physics-based normative energy models using Bayesian methods.

Some techniques for predicting retrofit savings do not use physical, statistical, or hybrid models. Both Kumbaroğlu and Madlener [33] and Menassa [34] approach energy retrofits from an economic and financial perspective. While significant, they do not thoroughly discuss methods for predicting energy savings. Other researchers predict energy savings using pre- and post-retrofit measurements of energy use, both for small case studies [35] and for large groups of buildings taking place in retrofit programs $[36]$.

While existing methods for predicting retrofit savings are useful in some contexts, they have their 
faults. Uncalibrated physical models are often inaccurate, and hybrid approaches that calibrate physical models are often subjective and overly dependent on engineering judgement[37]. Often, the time, cost, and expertise needed to construct and use a detailed physics-based simulation model or a hybrid model is considerable when compared to the expected cost savings due to implementing a retrofit. Typically, it is not until after a detailed model is built that a building owner will know if the expected savings justified the cost of the model. However, large databases of building characteristics and energy use are becoming more widely available, indicating the use of statistical models for predicting retrofit savings as the more cost-effective approach. In addition, many physical models fail to quantify uncertainty in savings predictions, whereas most statistical models are by their nature capable of estimating uncertainty on predictions. Furthermore, using empirical data may account for factors that are prohibitively difficult to include in simulation models (e.g., occupant behavior, unintended operation of building systems, and interactive effects). Lastly, decision makers may be more confident in savings estimates based on actual measured data than those based on simulated data. Statistical models in the literature are often significantly complex and are constructed for specific building types and environments, meaning they are not readily applicable to more general circumstances. Methods based on data gathered before and after retrofit programs are promising, but pre- and post-retrofit data are difficult to obtain, and are typically only for specific geographic areas or retrofit types.

\section{Data}

\subsection{Building Performance Database}

The U.S. Department of Energy Building Performance Database (BPD) contains measured data on energy consumption, characteristics, and equipment for 870,000 buildings $(742,500$ residential and 127,500 commercial). Data were collected from buildings all over the U.S., with a large variety of building types, sizes, ages, operational characteristics, and equipment. The data were submitted by over 50 public, private, and government organizations; some submitted data voluntarily, while some were obliged to by local disclosure ordinances (e.g., New York, San Francisco, Seattle, Washington D.C.). The BPD includes existing building databases such as CBECS [38], RECS [39], and CEUS [40].

The BPD website [41] provides tools for visualizing the data in the BPD, and the BPD application program interface (API) [42] provides developers with back-end access to the data. The BPD 
enables users to compare the energy use and characteristics of their building to other similar buildings, identify types of buildings that will benefit from certain kinds of retrofits, and estimate the energy savings expected as a result of particular retrofits. Lawrence Berkeley National Laboratory (LBNL) develops the BPD API by designing analysis tools and features that inform users while maintaining data anonymity.

Data submitted to the BPD are cleansed and processed to ensure they meet minimum requirements, are physically reasonable, and are internally consistent; more details on the methods used can be found in [43]. In [44], Mathew et al. describe cleaning and mapping of data for the BPD, and summarize data distributions. Nearly all buildings in the BPD contain the following information:

- one full year of energy use data (from electricity, natural gas, and other sources),

- gross floor area,

- location information (zip code, city, state, ASHRAE climate zone), and

- building use type (e.g., office, grocery store, single-family house).

A small portion of the buildings have information on

- building systems (e.g., lighting, heating, cooling, windows),

- operational characteristics (number of occupants, operating hours), and

- more (e.g., year built, ENERGY STAR rating).

The energy data in the BPD are aggregated into annual whole-building energy use, separated into 4 types (electric, fuel, site, and source), and reported as energy use intensity (EUI), rather than actual energy use. Energy data are only allowed in the BPD if they are measured; estimated energy totals are discarded. Aside from energy data, the majority of the data are self-reported and may not be entirely reliable. It is important to note that measuring building information by surveying building owners introduces uncertainty into the data, but the amount of uncertainty is unknown. While the BPD contains a large number of buildings, only approximately $5 \%$ have detailed information on building systems and operational characteristics.

\subsection{Analysis Peer Group}

In the analysis shown here, we focus on commercial buildings with reported gross floor area, source EUI, number of occupants, average weekly operating hours, and year built. We limit the 
analysis to buildings smaller than $300,000 \mathrm{ft}^{2}$, with annual source EUI less than $200 \mathrm{MWh} /(1000$ $\mathrm{ft}^{2}$ ), with fewer than 1000 occupants, and built after the year 1900. For model simplicity, and to avoid overfitting, we aggregate building type, heating type, cooling type, lighting type, and wall type into broader categories than used by the BPD, and we round year built down to the nearest 20 years. The resulting peer group consists of 926 commercial buildings.

While this analysis is conducted for a wide variety of commercial buildings, the methods described here are equally applicable to other groups of buildings (e.g., buildings in a particular state or buildings of a certain building type). The only caveat is the sparseness of the BPD; selecting a more specific peer group often results in too few buildings with reported data on the equipment types of interest.

Figure 1 shows the distribution of EUI for each building type. There is a large range of median EUIs, indicating building type has significant influence on EUI. Food sales buildings have the highest median EUI, likely due to the significant amount of cooling necessary to store food products. Intuitively, warehouses (the large majority of which are not refrigerated) have the lowest median EUI. While the distribution of EUIs for office buildings is centered fairly tightly around 60 $\mathrm{MWh} /\left(1000 \mathrm{ft}^{2}\right)$, health care buildings have significant variance around the median EUI despite having a substantial sample size.

Figure 2 shows the distribution of EUI for buildings grouped by their wall type. Relative to Figure 1, there is a smaller range of median EUIs, indicating wall type has a more subtle effect on EUI. Intuitively, window walls tend to have higher EUIs than buildings with brick or concrete walls, but only marginally so. Most buildings with unknown wall type have EUIs near $65 \mathrm{MWh} /(1000$ $\mathrm{ft}^{2}$ ), but there is a significant number of outliers.

Figure 3 shows the distribution of EUI for buildings grouped by types of window layers. Relative to both Figures 1 and 2, there is a smaller range of median EUIs, indicating no clear relationship between window layers and EUI. Contrary to intuition, buildings with single-pane windows appear to have slightly lower EUIs than buildings with double-pane windows (even though this difference is likely not statistically significant).

Figures 1, 2, and 3 identify building characteristics that are commonly associated with high and low EUI, but it is important not to overinterpret these results; confounding effects can be disguised when observing the dependence of EUI on only individual characteristics. For example, Figure 3 shows buildings with single-pane windows have lower EUIs than buildings with doublepane windows. This is unlikely because single-pane windows provide less thermal insulation than 


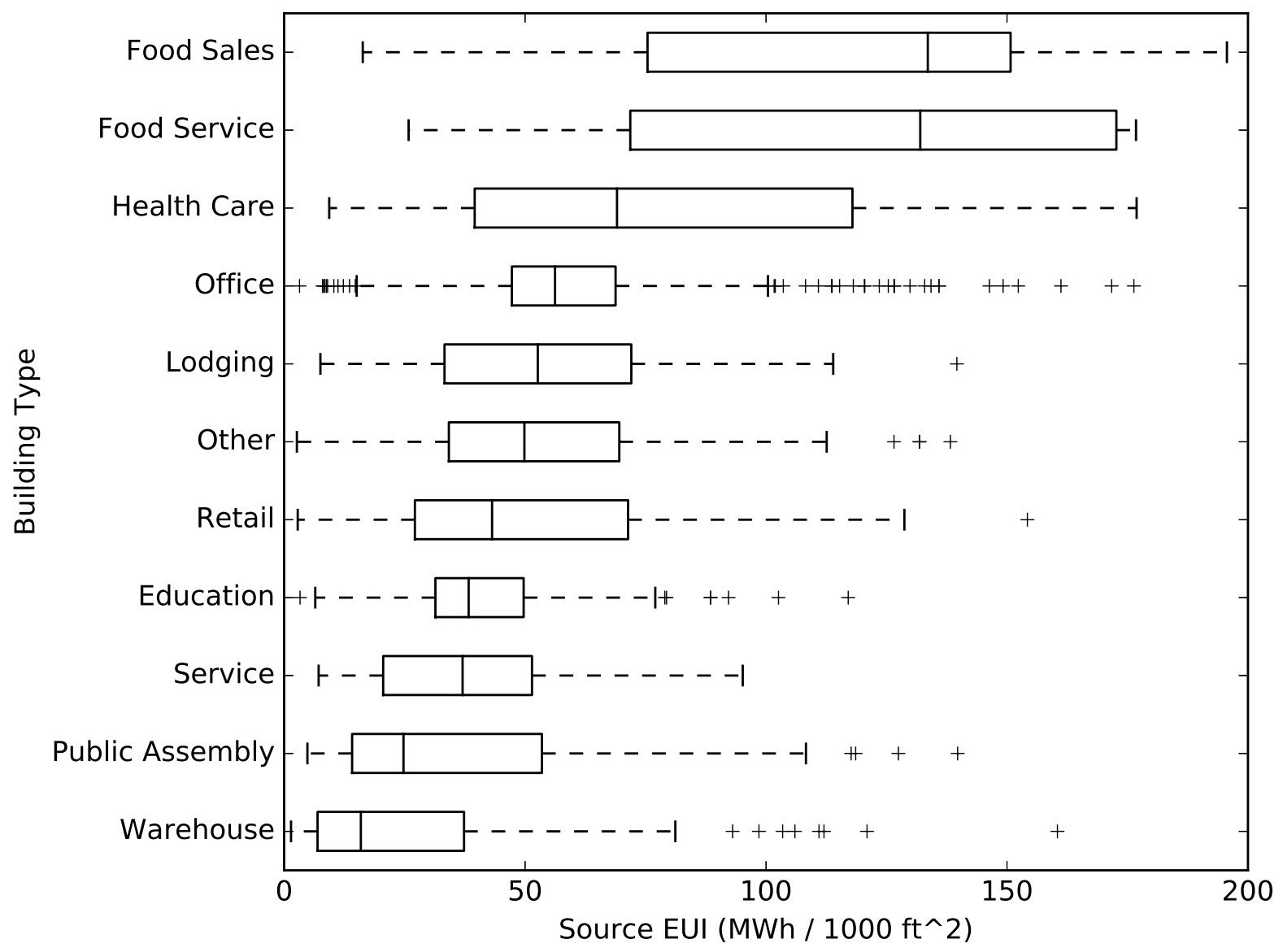

Figure 1: Boxplots showing distribution of annual source EUI for buildings of each use type, sorted by median value. 


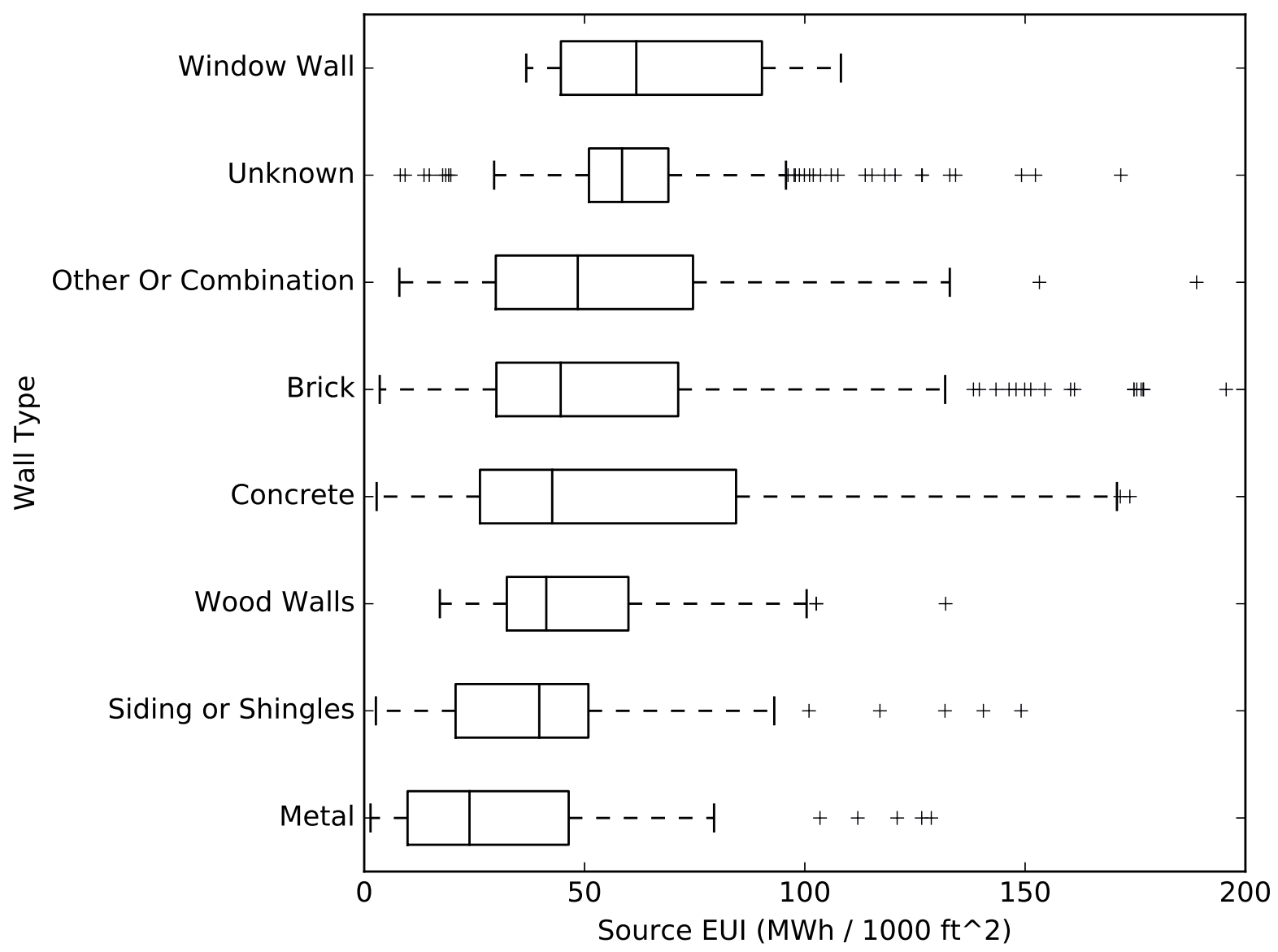

Figure 2: Boxplots showing distribution of annual source EUI for buildings with each wall type, sorted by median value. 


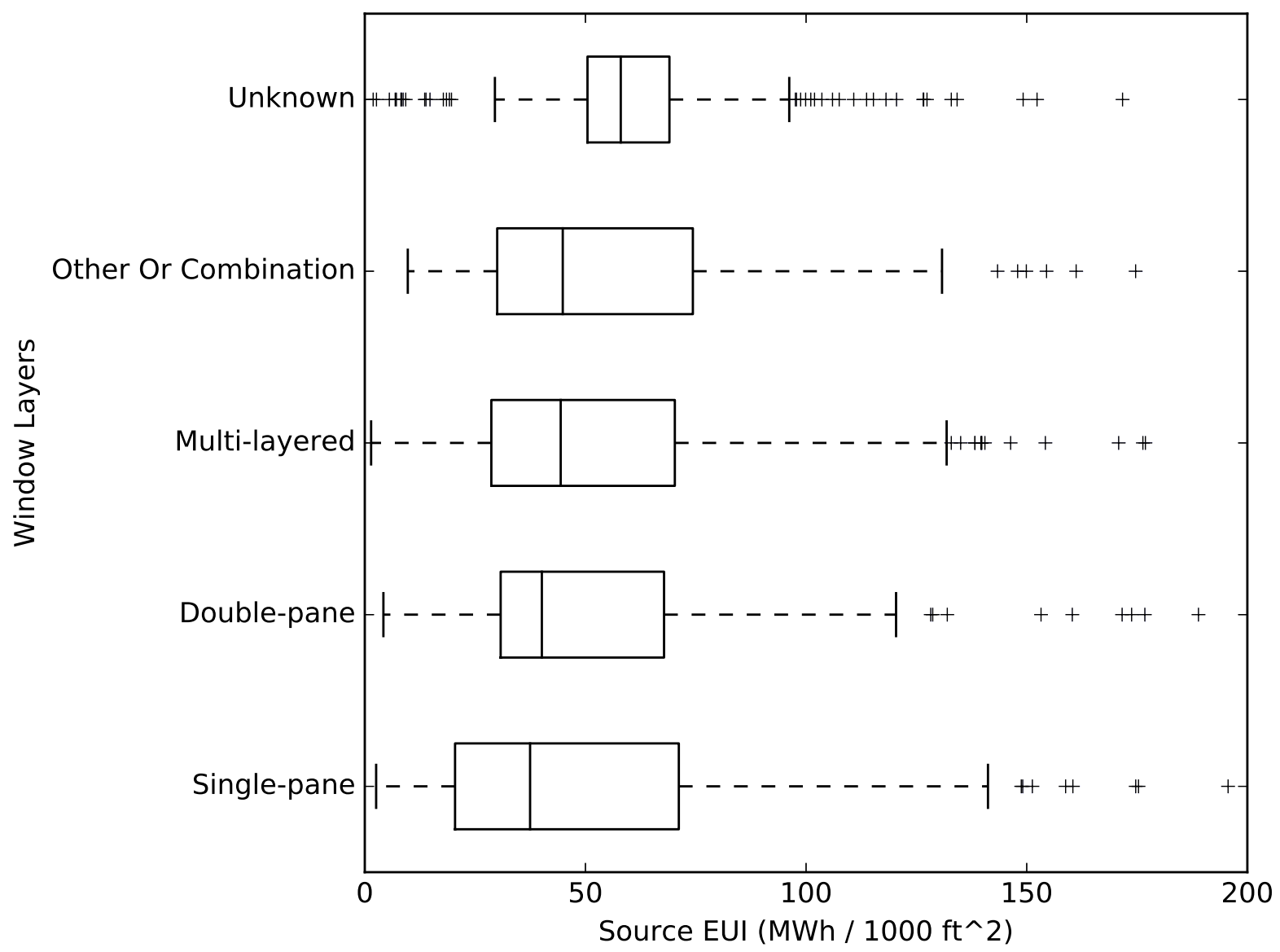

Figure 3: Boxplots showing distribution of annual source EUI for buildings with each type of window layers, sorted by median value. 
double-pane windows. Instead, it may be that buildings with single-pane windows tend to have other characteristics that cause lower EUI (e.g., more moderate climates or lower occupant density). These confounding factors are one of the reasons a multivariate regression model is needed.

\section{Regression Model}

In order to estimate the energy savings due to implementing a particular retrofit, we developed a multivariate linear regression model that would:

- provide estimates of EUI based on empirical data while requiring few modeling assumptions,

- isolate the effect of particular building characteristics and equipment on EUI,

- be capable of predicting EUI for hypothetical combinations of predictors that are not present in the database,

- provide estimates and residuals with well-understood statistical properties, and

- be robust, well-known, easy to use, and computationally efficient.

A regression model was selected for this work, but we do not imply this is the only or the best model for this purpose. We encourage the investigation of alternate models.

Annual source EUI was chosen as the response variable of the regression model because it allows direct comparison of both large and small buildings and buildings that use multiple fuel sources (electricity, natural gas, fuel oil, etc.). Utilizing annual totals for energy use obscures seasonal variation in energy use and savings, but since practitioners are typically interested in long-term energy savings, annual totals are appropriate for this analysis. The predictors in the regression model encompass most of the data fields in the BPD, and were chosen based on a combination of physical intuition, correlation analysis, and availability of data. For example, it is intuitive that climate will impact a building's EUI because a significant portion of energy use in commercial buildings is due to heating and cooling; thus, climate was chosen as a predictor. Similarly, heating, cooling, and lighting systems will impact energy use, so they were chosen as predictors. Other predictors were chosen by observing the correlation between them and EUI (e.g., see Figures 1, 2, and 3). Figure 4 shows that source EUI is somewhat correlated $(\rho=0.35)$ with operating hours. This level of correlation for a peer group containing 926 buildings is evidence for a linear relationship; therefore operating hours was chosen as a predictor. Some fields were not chosen because very few 


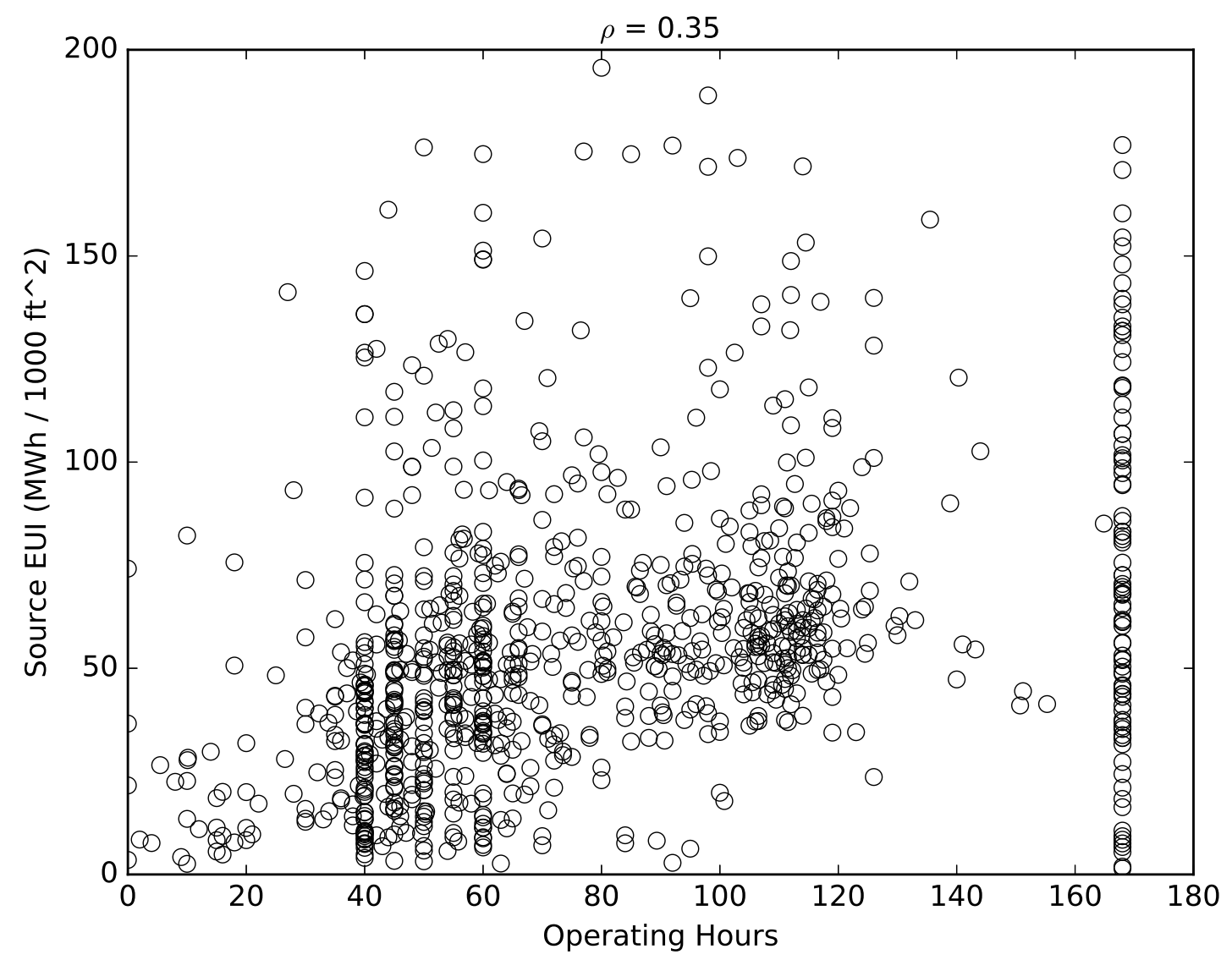

Figure 4: Scatterplot of source EUI and average weekly operating hours, with Pearson correlation coefficient $\rho$.

buildings reported data (e.g., LEED score, wall insulation). Some fields are highly correlated with other fields (e.g., wall type and roof type), so only one of the fields was chosen. Since floor area was used when normalizing energy use to EUI, and since EUI and floor area are very weakly correlated, floor area was not chosen as a predictor. Since energy use was normalized by floor area, number of occupants was also normalized and occupant density was chosen instead. The numerical variables operating hours and occupant density are centered by subtracting the mean then normalized by dividing by the standard deviation so that all model coefficients will be in the same units and can be compared to one another more easily. The numerical variable year built is rounded down to the nearest 20 years and treated as a categorical variable because this allows a nonlinear relationship between EUI and year built.

The regression model includes a constant term, one predictor for each of the numerical variables (occupant density and operating hours), and several predictors for each of the categorical variables 
(year built, building type, climate zone, heating type, cooling type, lighting type, air flow control type, wall type, window type, and window layers). For numerical variables, the predictor in the model is centered by subtracting the variable's mean then dividing by its standard deviation. For categorical variables, the predictors in the model are indicator variables. For a categorical variable with $N$ possible values, the model contains $N-1$ indicators associated with that variable. This prevents linear dependence between categorical variables. The contribution of the $N^{\text {th }}$ value of each categorical variable to EUI is captured in the constant term $\beta_{0}$, and the model is still capable of predicting EUI for a building with the $N^{\text {th }}$ value of a categorical variable. The values of the categorical variables are listed in the appendix, with the $N^{\text {th }}$ value listed last.

We experimented with several alternate forms of the regression model. We tested using the logarithm of EUI instead of just EUI and we tested nonlinear functions of the other numerical variables, but none of these models predicted EUI significantly better than the selected model. We observed a slight increase in accuracy when predicting EUI for buildings used to fit the model, but not when predicting EUI for buildings not used to fit the model; this indicated overfitting was likely. We also experimented with model terms that combined multiple predictors. Intuitively, the efficiency of a building's heating system will have less impact on EUI if the building is in a mild climate, so we evaluated the use of indicators for combinations of heating type and climate zone. While this form of the model provided a mildly better fit to the data, the coefficient estimates for many combinations were based on very few data points, and overfitting was again a concern.

The model was fit to the 926 buildings in the peer group described in Section 3.2 using ordinary least squares (i.e., minimizing the sum of the squared residuals). Residual analysis methods were used to confirm the assumptions made in using a linear regression model were not violated: the distribution of residuals is approximately normally distributed with zero mean and there is no apparent correlation between model predictions and externally studentized residuals (see [45]).

Considering the large number of predictors in the model, multicollinearity between predictors was also investigated. We confirmed the predictor matrix is full rank and that the condition number of the predictor matrix (78.24) is not too large[45]. We also computed variance inflation factors (VIFs) for each of the predictors[45]. A regression model with moderate multicollinearity can still be useful, as long as extrapolation is not done using the predictors exhibiting multicollineartiy. Therefore, predictors with unreasonably high VIFs (i.e., greater than 10) were removed from the model, and predictors with moderate VIFs (i.e., greater than 5) were marked and excluded as potential retrofit values, but were kept in the model. For example, some climate zones were found 
to be moderately correlated with heating and cooling types, so heating and cooling retrofits are not considered, but since window and wall characteristics showed little correlation with other predictors, model predictions for hypothetical values of these variables can be trusted.

Finally, the model was verified using cross-validation: the model was fit to several randomlyselected subsets of the data and the resulting predictions for the remaining data were compared. The accuracy of the predictions was not significantly different when different subsets of data were used to fit the model.

Figure 5 shows EUI predicted by the model for all buildings in the peer group plotted against measured EUI for the same buildings. The blue line has zero intercept and unity slope, representing all values where model predictions are equal to measurements. Overall, the model does a reasonable job of predicting EUI $\left(R^{2}=0.40\right)$, despite underpredicting (points below the blue line) for higher EUIs and overpredicting (points above the blue line) for lower EUIs. The difference between model predictions and measurements could be due to many factors: the data may contain errors due to self-reporting, variables that influence EUI may not be measured and thus are not in the model, and the form of the model may not reflect the true behavior of the buildings. It is possible that other models would predict EUI more accurately, but these models may be more complex and difficult to develop. An important aspect of this work is that model uncertainty is propagated into the savings estimates described in Section 5. Depending on the cost of the retrofit being considered, a building owner or policy maker may not be satisfied with the level of uncertainty in the savings estimates and may decide that development of a more accurate model to help reduce uncertainty is worthwhile.

Figure 6 shows the resulting model coefficients. Each coefficient is represented by its expected value and the $95 \%$ confidence interval on its estimated value [45]. Coefficients with expected values to the right of the dotted line are associated with larger values of EUI, while coefficients to the left are associated with smaller values. Coefficients with wide confidence intervals are estimated less precisely than those with narrow confidence bands. For example, higher occupant density and operating hours are associated with higher EUI, and their estimates are quite precise compared to the other coefficients. Coefficients for numerical variables are estimated more precisely than categorical variables, likely because every building has data for the numerical variables, but there are few buildings with a particular value of a categorical variable. The high variability in the constant coefficient is likely due to the same effect because it encompasses a combined effect on EUI of all of the categorical variables. 


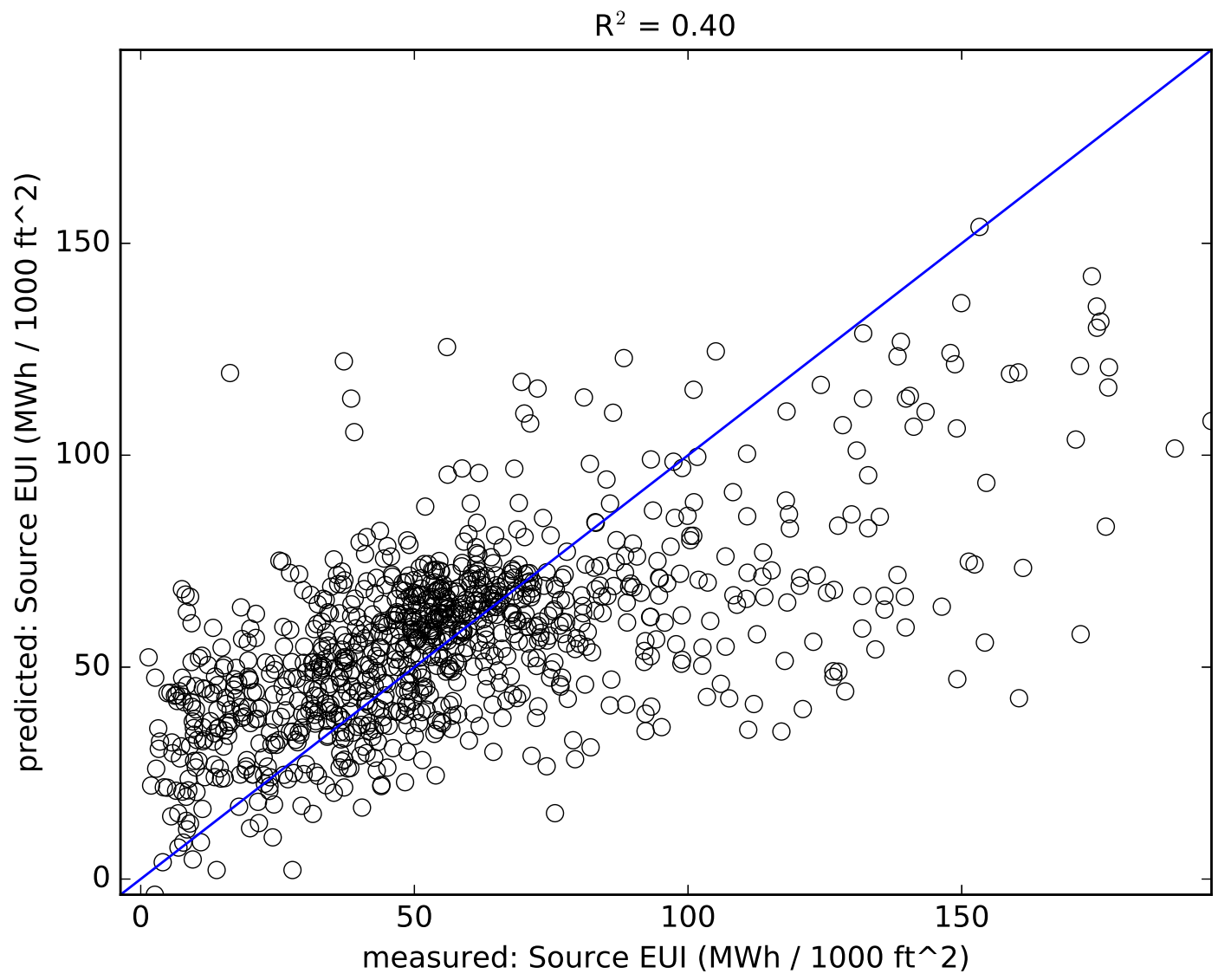

Figure 5: Model predictions of EUI plotted against measured EUI for each building in peer group (black circles), with coefficient of determination $R^{2}$. The blue line represents all points where the model prediction is equal to the measurement. 


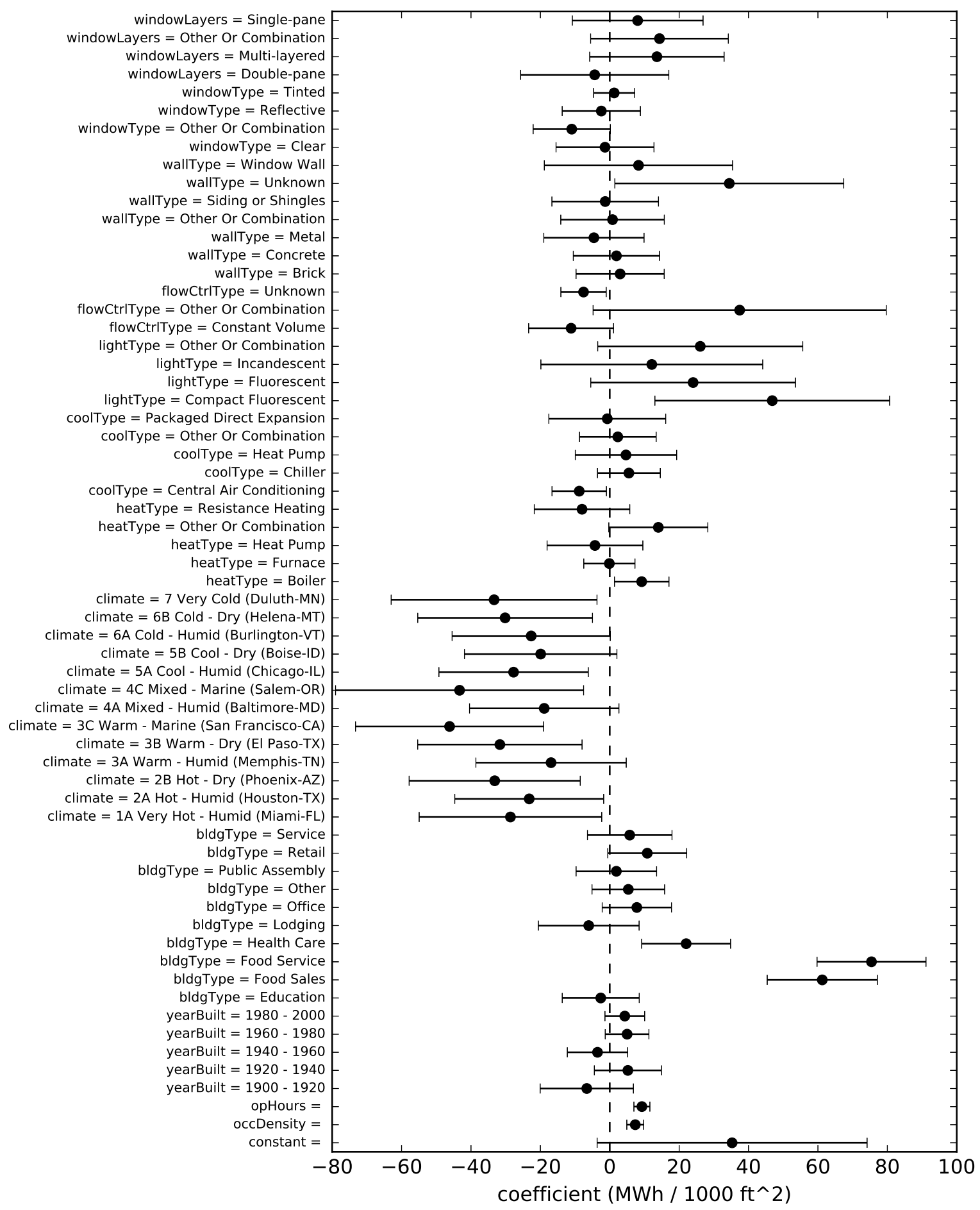

Figure 6: Mean and 95\% confidence interval of estimates of regression model coefficients. 
The resulting model coefficients are not always consistent with other analyses. As indicated in both Figures 2 and 6, buildings with window walls have higher EUI than buildings with concrete or brick walls. However, contrary to Figure 3 but consistent with physical intuition, Figure 6 indicates buildings with single-pane windows have higher EUI than buildings with double-pane windows. This illustrates a key feature of this regression model: it can isolate the effects of multiple parameters when confounding effects are present.

\section{Savings Predictions}

The coefficients in Figure 6 can be used not only to compare the relative contributions of different building characteristics and equipment; they can also be used to predict EUI for buildings with hypothetical combinations of the model predictors. For example, the database may not contain any buildings with both double-pane windows and no heating system, but the model has predictors for both and therefore can predict the EUI for such a building. In order to estimate the energy savings due to retrofitting a particular building component, the approach can first be used to predict EUI for a hypothetical building with the old component, then to predict EUI for a building with the new component, and the difference between the predictions can be interpreted as the savings.

While estimating savings for an individual building maybe be useful in some contexts, policy makers or building portfolio owners may be interested in the savings expected when applying retrofits to several buildings. To estimate the savings for an entire peer group, we create a hypothetical pre-retrofit peer group where each building is identical to the actual building, except for the value of the variable representing the retrofit. Likewise for a post-retrofit peer group. For example, consider estimating savings when retrofitting single-pane windows to double-pane windows, and say the actual database contains a 50,000 $\mathrm{ft}^{2}$ office building in climate zone 4C with multi-layered windows. The pre-retrofit peer group will contain a corresponding $50,000 \mathrm{ft}^{2}$ office building in climate zone $4 \mathrm{C}$, but it will have single-pane windows, and likewise for the post-retrofit peer group and double-pane windows. For every building in the peer group, EUI is predicted for the corresponding buildings in the pre- and post-retrofit peer groups, and the difference between those predictions (normalized by the pre-retrofit EUI prediction to yield a relative change) is tabulated. The collection of these differences can be interpreted as samples from a distribution of savings from the buildings in the peer group. Once the distribution of savings is computed, it can be inspected to make statements about the likelihood of achieving particular levels of savings. For example, if the first quartile of the savings distribution is $10 \%$, there is a $75 \%$ chance that a building from the 


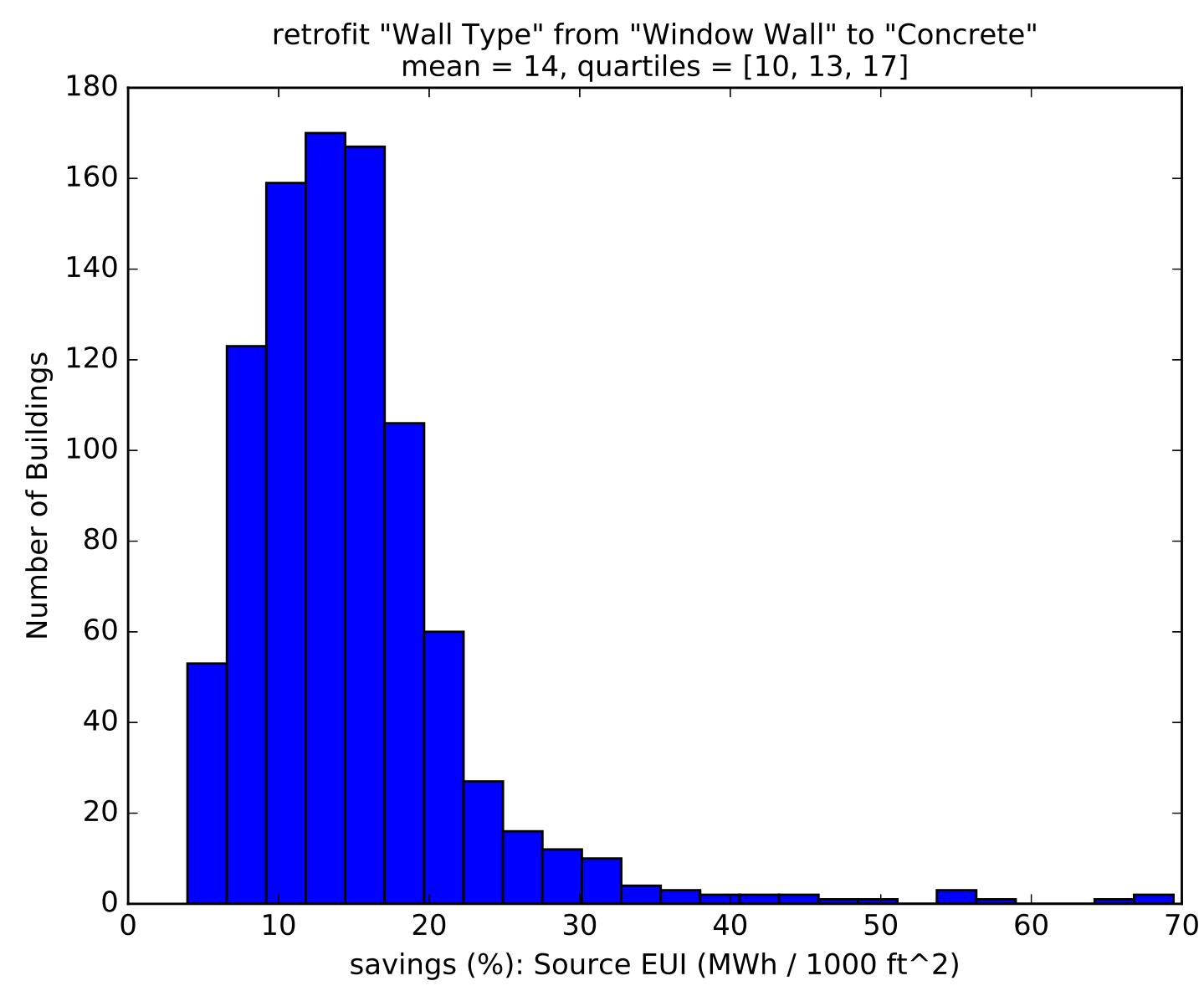

Figure 7: Histogram of estimated savings due to retrofitting walls from window walls to concrete. Savings are expressed as the difference between pre- and post-retrofit EUI, as a percentage of pre-retrofit EUI.

peer group will reduce EUI by at least $10 \%$ of pre-retrofit EUI when implementing the retrofit.

Figure 7 shows a histogram of estimated EUI savings for buildings in the peer group when changing from window walls to concrete walls. It is unlikely that a building owner would actually undertake a retrofit as serious as modifying the walls of a building, but the results can be used to compare EUI for buildings with the two wall types. Intuitively, buildings with the more insulative concrete walls have lower estimated EUIs (positive savings). The savings estimates are reasonable based on physical intuition, i.e., half of the buildings save between $9 \%$ and $17 \%$. The highest savings predicted by the model are over $60 \%$, contrary to physical intuition, but only a small proportion of buildings have such high savings estimates.

Figure 8 shows a histogram of savings estimates for the peer group when retrofitting from single-pane windows to double-pane windows. Retrofitting windows in this way is commonly done; 


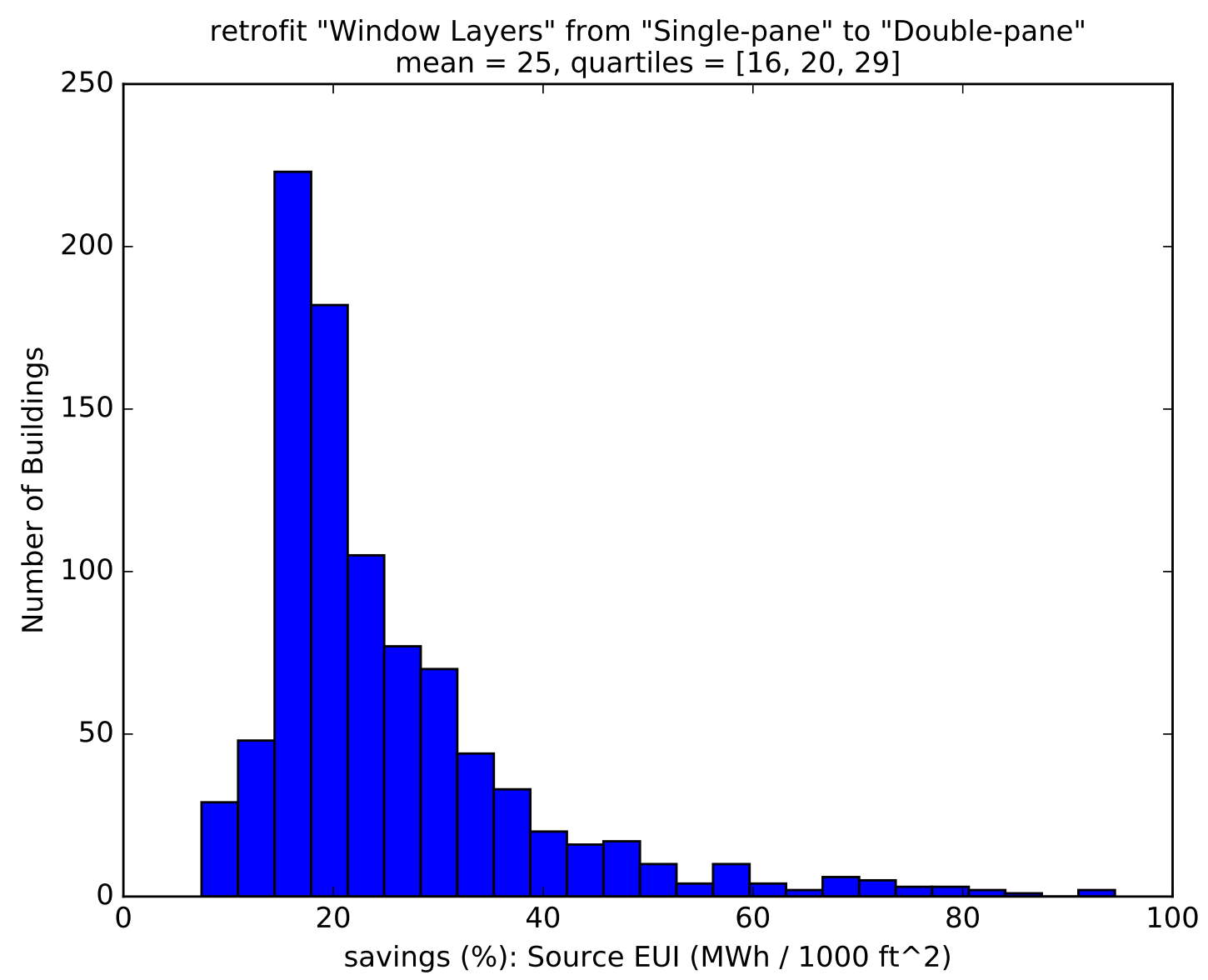

Figure 8: Histogram of estimated savings due to retrofitting windows from single-pane to double-pane. Savings are expressed as the difference between pre- and post-retrofit EUI, as a percentage of pre-retrofit EUI.

installation costs are typically reasonable, the effect of the retrofit on energy use is intuitive, and achieved savings are predictable. The model predicts savings between $16 \%$ and $28 \%$ for roughly half of the buildings, and no buildings are expected to use more energy after the retrofit. Again, savings estimates are physically unreasonable for only a small proportion of buildings.

The savings predicted by the model are consistent with physical intuition in the majority of cases, but there are some cases where the estimates are clearly inaccurate. For example, the model predicts negative savings (increased EUI) for the majority of buildings when retrofitting from T12 to T8 fluorescent lights. The savings predictions may be inaccurate for a number of reasons:

- For certain types of equipment, there simply are not enough buildings in the dataset for the model to characterize the effect of the equipment on EUI very well. This effect is minimized by preventing savings predictions for predictors with very little informative data, but inaccuracy 
in the estimate for one model coefficient can influence the estimates of all model coefficients.

- There are probably building characteristics that influence energy use, but are not included in the model because they are not reported in the database. For example, the model includes terms for occupant density and operating hours, but the BPD doesn't contain information on how many personal computers, refrigerators, or space heaters are used in a building. The effect of occupant behavior on energy use is not well known $[26,46]$, but may have large effect on energy use $[47,46]$.

- Some of the predictors in the model may be strongly correlated, causing the model to conflate the effects of the predictors. For example, heating and cooling systems are often chosen based on the local climate.

- The model assumes that the influence of different building characteristics are independent of one another, but there may be interactive effects. For example, the savings expected when retrofitting a building's heating system will be lower for a building in a mild climate (e.g., San Francisco) than for a building in a more extreme climate (e.g., New York). We experimented with a model that uses indicators for combinations of multiple predictors, but the sparseness of the data prohibited this approach.

Savings estimates like those in Figure 8 provide building owners and policy makers with the information needed to intelligently decide on retrofit investments. For each potential retrofit, stakeholders can use these savings estimates to calculate a probability distribution of energy cost reductions, and compare this to the cost of implementing the retrofit. This allows potential retrofits to be classified according to expected benefits, and according to the likelihood the actual benefits will deviate from the expected benefits. A building owner will prefer a retrofit with high expected savings, and low uncertainty in the savings estimates, but such a retrofit may not exist. Rather, a building owner may have to decide between a retrofit with high expected savings and high uncertainty, and a retrofit with low expected savings and low uncertainty. An investor may be willing to make a more risky investment if the potential benefits are high enough. In addition, these savings estimates can identify situations in which no investment should be made. Depending on the retrofit being considered, the uncertainty in the savings estimates can be large relative to the expected savings, and investing in such a retrofit may be as likely to lose money as to make money. 


\section{Concluding Remarks}

This work explores the development of a model that provides building owners and policy makers estimates of expected energy savings that allow comparison of investments in energy efficiency retrofits. A major factor limiting such investments is the uncertain relationship between the amount invested and the energy savings achieved. Our resulting algorithmic approach provides probabilistic estimates of energy savings so that investors can properly weigh risk. For example, the methods described here can answer questions such as: What is the probability that upgrading my building's heating system will reduce energy use by at least $15 \%$ ? Knowing the cost of the heating system upgrade and the price of energy, an investor can directly answer the question: What is the chance my investment will return a profit?

The techniques described here are useful for both individual building owners, and for portfolio owners and policy makers. Suppose a city or state official is interested in subsidizing energy efficiency improvements to local buildings. Savings estimates for various potential retrofits can be computed and compared to one another. The official can identify retrofits that maximize savings and choose to subsidize retrofits accordingly. By selecting an analysis peer group that reflects the local building stock, savings estimates are tailored to the population of buildings in which the retrofits would be implemented.

The method presented here is based on empirical data that is available at low cost. Even for an individual building, completing a detailed analysis and constructing a physical model to predict energy consumption with different equipment can be costly and time consuming. Building detailed models of a portfolio of buildings or of all the buildings in a city or state is clearly unfeasible. This method for savings estimates does not require the time, money, or expertise necessary for physical modeling.

In summary, this work expands the current state of research by providing a methodology for investigating building energy retrofit investments. We show how building data can inform a statistical model that relates energy use to building characteristics. We show how this model can be used to estimate the likelihood of implementing candidate retrofits achieving a particular level of energy savings. Lastly, we discuss how these savings estimates can be used to compare different retrofits and can provide an understanding of risk that is necessary for deciding on potential investments intelligently.

Some of the inaccuracies in the regression model are due to lack of data. While the BPD contains 870,000 buildings, this represents less than $1 \%$ of the U.S. building stock [1], and only 
about $5 \%$ of building in the $\mathrm{BPD}$ report building equipment information. However, recent trends indicate the availability of building data will rapidly increase in the near future. Since data are collected from any contributor, there is no guarantee that the data in the BPD are representative of the national stock, but in cities with disclosure ordinances (e.g., San Francisco, New York, Seattle, Washington D.C.), the BPD likely contains a near-complete sample of commercial buildings. As the data in the BPD increase in both quantity and quality, the regression model will become better able to provide reliable savings estimates.

A significant improvement to this work would be verification of savings predictions using detailed building information and measured energy data from before and after retrofit retrofit implementation. Unfortunately, these data are not readily available. However, this work has shown the potential benefits of retrofit savings estimates, and thereby may motivate the collection of more data from actual retrofit programs so that savings estimates can be further validated.

\section{Acknowledgements}

This work was performed at Lawrence Berkeley National Laboratory under DOE contract DEAC02-05CH11231. We gratefully acknowledge partial support from the Assistant Secretary for Energy Efficiency and Renewable Energy of the DOE.

\section{Appendix}

Table 1 lists the values of each of the categorical variables.

\begin{tabular}{|l|l|}
\hline Variable & Values \\
\hline yearBuilt & $1900-1920$ \\
& $1920-1940$ \\
& $1940-1960$ \\
& $1960-1980$ \\
& $1980-2000$ \\
& $2000-2020$ \\
\hline bldgType & Education \\
& Food Sales \\
& Food Service \\
& Health Care
\end{tabular}




\begin{tabular}{|c|c|}
\hline & $\begin{array}{l}\text { Lodging } \\
\text { Office } \\
\text { Other } \\
\text { Public Assembly } \\
\text { Retail } \\
\text { Service } \\
\text { Warehouse }\end{array}$ \\
\hline climate & $\begin{array}{l}\text { 1A Very Hot - Humid (Miami-FL) } \\
\text { 2A Hot - Humid (Houston-TX) } \\
\text { 2B Hot - Dry (Phoenix-AZ) } \\
\text { 3A Warm - Humid (Memphis-TN) } \\
\text { 3B Warm - Dry (El Paso-TX) } \\
\text { 3C Warm - Marine (San Francisco-CA) } \\
\text { 4A Mixed - Humid (Baltimore-MD) } \\
\text { 4C Mixed - Marine (Salem-OR) } \\
\text { 5A Cool - Humid (Chicago-IL) } \\
\text { 5B Cool - Dry (Boise-ID) } \\
\text { 6A Cold - Humid (Burlington-VT) } \\
\text { 6B Cold - Dry (Helena-MT) } \\
\text { 7 Very Cold (Duluth-MN) } \\
\text { Unknown }\end{array}$ \\
\hline heatType & $\begin{array}{l}\text { Boiler } \\
\text { Furnace } \\
\text { Heat Pump } \\
\text { Other Or Combination } \\
\text { Resistance Heating } \\
\text { Unknown }\end{array}$ \\
\hline coolType & $\begin{array}{l}\text { Central Air Conditioning } \\
\text { Chiller } \\
\text { Heat Pump } \\
\text { Other Or Combination } \\
\text { Packaged Direct Expansion }\end{array}$ \\
\hline
\end{tabular}




\begin{tabular}{|c|c|}
\hline & Unknown \\
\hline lightType & $\begin{array}{l}\text { Compact Fluorescent } \\
\text { Fluorescent } \\
\text { Incandescent } \\
\text { Other Or Combination } \\
\text { Unknown }\end{array}$ \\
\hline flowCtrlType & $\begin{array}{l}\text { Constant Volume } \\
\text { Other Or Combination } \\
\text { Unknown } \\
\text { Variable Volume }\end{array}$ \\
\hline wallType & $\begin{array}{l}\text { Brick } \\
\text { Concrete } \\
\text { Metal } \\
\text { Other Or Combination } \\
\text { Siding or Shingles } \\
\text { Unknown } \\
\text { Window Wall } \\
\text { Wood Walls }\end{array}$ \\
\hline window Type & $\begin{array}{l}\text { Clear } \\
\text { Other Or Combination } \\
\text { Reflective } \\
\text { Tinted } \\
\text { Unknown }\end{array}$ \\
\hline windowLayers & $\begin{array}{l}\text { Double-pane } \\
\text { Multi-layered } \\
\text { Other Or Combination } \\
\text { Single-pane } \\
\text { Unknown }\end{array}$ \\
\hline
\end{tabular}

Table 1: Values of categorical variables. 


\section{References}

[1] D \& R International, Ltd., 2011 buildings energy data book, Tech. rep., United States Department of Energy (Mar. 2012).

[2] J. H. Williams, A. DeBenedictis, R. Ghanadan, A. Mahone, J. Moore, W. R. M. III, S. Price, M. S. Torn, The technology path to deep greenhouse gas emissions cuts by 2050: The pivotal role of electricity, Science 335 (6064) (2012) 53-59. doi:10.1126/science.1208365.

[3] Z. Ma, P. Cooper, D. Daly, L. Ledo, Existing building retrofits: Methodology and state-ofthe-art, Energy and Buildings 55 (2012) 889-902. doi:10.1016/j.enbuild.2012.08.018.

[4] F. Noris, G. Adamkiewicz, W. W. Delp, T. Hotchi, M. Russell, B. C. Singer, M. Spears, K. Vermeer, W. J. Fisk, Indoor environmental quality benefits of apartment energy retrofits, Building and Environment 68 (2013) 170-178. doi:10.1016/j.buildenv.2013.07.003.

[5] D. Popescu, S. Bienert, C. Schützenhofer, R. Boazu, Impact of energy efficiency measures on the economic value of buildings, Applied Energy 89 (1) (2012) 454-463. doi:10.1016/j.apenergy.2011.08.015.

[6] S. Wang, C. Yan, F. Xiao, Quantitative energy performance assessment methods for existing buildings, Energy and Buildings 55 (2012) 873-888. doi:10.1016/j.enbuild.2012.08.037.

[7] H. Zhao, F. Magoulès, A review on the prediction of building energy consumption, Renewable and Sustainable Energy Reviews 16 (6) (2012) 3586-3592. doi:10.1016/j.rser.2012.02.049.

[8] V. Siddharth, P. V. Ramakrishna, T. Geetha, A. Sivasubramaniam, Automatic generation of energy conservation measures in buildings using genetic algorithms, Energy and Buildings 43 (10) (2011) 2718-2726. doi:10.1016/j.enbuild.2011.06.028.

[9] F. Al-Ragom, Retrofitting residential buildings in hot and arid climates, Energy Conversion and Management 44 (14) (2003) 2309-2319. doi:10.1016/S0196-8904(02)00256-X.

[10] F. Ascione, F. de Rossi, G. P. Vanoli, Energy retrofit of historical buildings: theoretical and experimental investigations for the modelling of reliable performance scenarios, Energy and Buildings 43 (8) (2011) 1925-1936. doi:10.1016/j.enbuild.2011.03.040. 
[11] M. M. Rahman, M. G. Rasul, M. M. K. Khan, Energy conservation measures in an institutional building in sub-tropical climate in Australia, Applied Energy 87 (10) (2010) 2994-3004. doi:10.1016/j.apenergy.2010.04.005.

[12] M. Santamouris, E. Dascalaki, Passive retrofitting of office buildings to improve their energy performance and indoor environment: the OFFICE project, Building and Environment 37 (6) (2002) 575-578. doi:10.1016/S0360-1323(02)00004-5.

[13] E. Dascalaki, M. Santamouris, On the potential of retrofitting scenarios for offices, Building and Environment 37 (6) (2002) 557-567. doi:10.1016/S0360-1323(02)00002-1.

[14] J. C. Lam, S. C. M. Hui, Sensitivity analysis of energy performance of office buildings, Building and Environment 31 (1) (1996) 27-39. doi:10.1016/0360-1323(95)00031-3.

[15] J. C. Lam, K. K. W. Wan, L. Yang, Sensitivity analysis and energy conservation measures implications, Energy Conversion and Management 49 (11) (2008) 3170-3177. doi:10.1016/j.enconman.2008.05.022.

[16] J. C. Lam, S. C. M. Hui, A. L. S. Chan, Regression analysis of high-rise fully air-conditioned office buildings, Energy and Buildings 26 (2) (1997) 189-197. doi:10.1016/S0378-7788(96)010341.

[17] J. C. Lam, K. K. W. Wan, D. Liu, C. L. Tsang, Multiple regression models for energy use in air-conditioned office buildings in different climates, Energy Conversion and Management 51 (12) (2010) 2692-2697. doi:10.1016/j.enconman.2010.06.004.

[18] S. Chidiac, E. Catania, E. Morofsky, S. Foo, A screening methodology for implementing cost effective energy retrofit measures in Canadian office buildings, Energy and Buildings 43 (2-3) (2011) 614-620. doi:10.1016/j.enbuild.2010.11.002.

[19] S. Chidiac, E. Catania, E. Morofsky, S. Foo, Effectiveness of single and multiple energy retrofit measures on the energy consumption of office buildings, Energy 36 (8) (2011) 5037-5052. doi:10.1016/j.energy.2011.05.050.

[20] A. M. Rysanek, R. Choudhary, Optimum building energy retrofits under technical and economic uncertainty, Energy and Buildings 57 (2013) 324-337. doi:10.1016/j.enbuild.2012.10.027. 
[21] E. Asadi, M. G. da Silva, C. H. Antunes, L. Dias, Multi-objective optimization for building retrofit strategies: A model and an application, Energy and Buildings 44 (2012) 81-87. doi:10.1016/j.enbuild.2011.10.016.

[22] E. Asadi, M. G. da Silva, C. H. Antunes, L. Dias, A multi-objective optimization model for building retrofit strategies using TRNSYS simulations, GenOpt and MATLAB, Building and Environment 56 (2012) 370-378. doi:10.1016/j.buildenv.2012.04.005.

[23] C. Diakaki, E. Grigoroudis, N. Kabelis, D. Kolokotsa, K. Kalaitzakis, G. Stavrakakis, A multiobjective decision model for the improvement of energy efficiency in buildings, Energy 35 (12) (2010) 5483-5496. doi:10.1016/j.energy.2010.05.012.

[24] S. Katipamula, T. A. Reddy, D. E. Claridge, Multivariate regression modeling, Journal of Solar Energy Engineering 120 (3) (1998) 177-184. doi:10.1115/1.2888067.

[25] J. Z. Kolter, J. F. Jr., A large-scale study on predicting and contextualizing building energy usage, in: Proceeding of the Twenty-Fifth AAAI Conference on Artificial Intelligence, San Francisco, California, USA, 2011, pp. 1349-1356.

[26] O. G. Santin, L. Itard, H. Visscher, The effect of occupancy and building characteristics on energy use for space and water heating in Dutch residential stock, Energy and Buildings 41 (11) (2009) 1223-1232. doi:10.1016/j.enbuild.2009.07.002.

[27] E. Beusker, C. Stoy, S. N. Pollalis, Estimation model and benchmarks for heating energy consumption of schools and sport facilities in Germany, Building and Environment 49 (2012) 324-335. doi:10.1016/j.buildenv.2011.08.006.

[28] D. Hsu, How much information disclosure of building energy performance is necessary?, Energy Policy 64 (2014) 263-272. doi:10.1016/j.enpol.2013.08.094.

[29] D. Hsu, Identifying key variables and interactions in statistical models of building energy consumption using regularization, Energy 83 (2015) 144-155. doi:10.1016/j.energy.2015.02.008.

[30] A. Kavousian, R. Rajagopal, M. Fischer, Determinants of residential electricity consumption: Using smart meter data to examine the effect of climate, building characteristics, appliance stock, and occupants' behavior, Energy 55 (2013) 184-194. doi:10.1016/j.energy.2013.03.086. 
[31] K. J. Baker, R. M. Rylatt, Improving the prediction of UK domestic energy demand using annual consumption data, Applied Energy 85 (6) (2008) 475-482. doi:10.1016/j.apenergy.2007.09.004.

[32] Y. Heo, R. Choudhary, G. A. Augenbroe, Calibration of building energy models for retrofit analysis under uncertainty, Energy and Buildings 47 (2012) 550-560. doi:10.1016/j.enbuild.2011.12.029.

[33] G. Kumbaroğlu, R. Madlener, Evaluation of economically optimal retrofit investment options for energy savings in buildings, Energy and Buildings 49 (2012) 327-334. doi:10.1016/j.enbuild.2012.02.022.

[34] C. C. Menassa, Evaluating sustainable retrofits in existing buildings under uncertainty, Energy and Buildings 43 (12) (2011) 3576-3583. doi:10.1016/j.enbuild.2011.09.030.

[35] F. Ardente, M. Beccali, M. Cellura, M. Mistretta, Energy and environmental benefits in public buildings as a result of retrofit actions, Renewable and Sustainable Energy Reviews 15 (1) (2011) 460-470. doi:10.1016/j.rser.2010.09.022.

[36] S. D. Cohen, C. A. Goldman, J. P. Harris, Measured energy savings and economics of retrofitting existing single-family homes: An update of the BECA-B database, Tech. Rep. LBL-28147, Lawrence Berkeley Laboratory (Feb. 1991).

[37] P. Raftery, M. Keane, J. O'Donnell, Calibrating whole building energy models: An evidence-based methodology, Energy and Buildings 43 (9) (2011) 2356-2364. doi:10.1016/j.enbuild.2011.05.020.

[38] United States Energy Information Administration, Commercial Buildings Energy Consumption Survey (Sep. 2015).

URL http://www.eia.gov/consumption/commercial/

[39] United States Energy Information Administration, Residential Energy Consumption Survey (Sep. 2015).

URL http://www.eia.gov/consumption/residential/

[40] California Energy Commission, California Commercial End-Use Survey (Sep. 2015). URL http://www.energy.ca.gov/ceus/ 
[41] United States Department of Energy, Building Performance Database (Jul. 2015).

URL https://bpd.lbl.gov/

[42] United States Department of Energy, Building Performance Database API Documentation (Jul. 2015).

URL https://sites.google.com/a/lbl.gov/bpd-api-documentation/

[43] C. Y. Custodio, T. Walter, L. N. Dunn, A. C. Mercado, R. E. Brown, P. A. Mathew, Data preparation process for the buildings performance database, Tech. Rep. LBL-6724E, Lawrence Berkeley National Laboratory (Aug. 2015).

[44] P. A. Mathew, L. N. Dunn, M. D. Sohn, A. C. Mercado, C. Y. Custodio, T. Walter, Big-data for building energy performance: Lessons from assembling a very large national database of building energy use, Applied Energy 140 (2015) 85-93. doi:10.1016/j.apenergy.2014.11.042.

[45] D. C. Montgomery, E. A. Peck, G. G. Vining, Introduction to Linear Regression Analysis, 5th Edition, Wiley, 2012.

[46] Z. Yu, B. C. M. Fung, F. Haghighat, H. Yoshino, E. Morofsky, A systematic procedure to study the influence of occupant behavior on building energy consumption, Energy and Buildings 43 (6) (2011) 1409-1417. doi:10.1016/j.enbuild.2011.02.002.

[47] E. M. Ryan, T. F. Sanquist, Validation of building energy modeling tools under idealized and realistic conditions, Energy and Buildings 47 (2012) 375-382. doi:10.1016/j.enbuild.2011.12.020. 